\title{
Reseña Bibliográfica: Sancho Rocher, L. (Coord.) (2015). La Antigüedad como paradigma. Espejismos, mitos y silencios en el uso de la historia del mundo clásico por los modernos. Zaragoza: Prensas de la Universidad de Zaragoza. 334 pp.
}

Palabras clave: Usos de la Antigüedad Grecorromana - Estados Unidos Nacionalsocialismo - Ilustración - India

Keywords: Uses of Greco-Roman Antiquity - United States - National Socialism Enlightenment - India

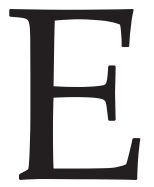

1 presente libro se centra en una serie de trabajos que analizan la utilización del pasado clásico en las sociedades modernas, que comprenden los siglos XVIII, XIX y XX. Los artículos nos muestran cómo, a lo largo de esos siglos, historiadores (incluso, muchos historiadores profesionales) y pensadores ejercieron de "creadores de mitos" mediante el uso de la historia clásica para justificar proyectos políticos, ideas, poderes y personajes que podríamos calificar como "grandes hombres". La utilización de la antigüedad clásica como una forma de justificación y, o de legitimación va de la mano con la necesidad de construir un escenario glorioso para el presente de esos siglos. En el caso del siglo XX, por ejemplo, los gobiernos totalitaristas europeos de Benito Mussolini y Adolf Hitler verán en la antigüedad clásica un recurso valioso para construir una sociedad anhelada, siguiendo los modelos grecorromanos. Así, pues, la reconstrucción del legado grecorromano persigue el objetivo principal de que esos modelos sirvan como una "guía de acción" para el presente.

Los trabajos compilados en el volumen se agrupan en tres secciones. La primera aborda el análisis de los usos del pasado grecorromano en las sociedades de los siglos XVIII y XIX. Esta sección, llamada “El arquetipo de las repúblicas clásicas en los siglos XVIII y XIX", comprende cuatro artículos.

El primero corresponde a César Fornis y se titula "Esparta como modelo y contramodelo en la Ilustración". En él, el historiador aborda dos formas de utilización de la polis griega en un contexto histórico marcado por los cambios culturales de la Francia del siglo XVIII. Por un lado, pensadores como Voltaire, Jacques Turgot y Bernard Mandeville veían a Esparta como un modelo nefasto a seguir en contraposición de una Atenas democrática y hasta "civilizada". Esparta era observada como una polis apenas urbanizada, salvaje y hasta ignorante. Atenas, en cambio, era "el modelo del progreso" a imitar si se quería lograr una sociedad avanzada y civilizada. Por otro lado, Esparta era vista como un modelo a igualar, ya que representaba un arquetipo esencial para los avances en educación y leyes. Quienes eran más "filoespartanos", entre ellos Rousseau, veían en 
la figura de Licurgo a un reformista digno de imitar, pues él había permitido que Esparta se afianzara como una sociedad virtuosa e incorruptible. La disputa entre Esparta como modelo y contramodelo se ve expresada en las obras producidas dedicadas al estudio de la polis del Peloponeso, que se dividen entre aquellas que negaban todo tinte de progreso siguiendo al modelo espartano y aquellas que veían a Esparta como un verdadero arquetipo a seguir y a Licurgo como la figura "paterna" de la polis.

El segundo trabajo, "El legado confederal griego en la constitución de los EEUU” de Clelia Martínez Maza, aborda la influencia del mundo clásico, y fundamentalmente el griego, en la conformación constitucional de las trece colonias. Los modelos políticos griegos se adaptaron a las exigencias del nuevo Estado y sus representantes políticos para el establecimiento de la constitución que iba a regir al naciente país. En este sentido, dos grupos se enfrentaban: los "federalistas", que propugnaban la existencia de un gobierno centralizado, y los "antifederalistas", que defendían una estructura gubernamental descentralizada, ya que la centralización solo llevaba a la ruina. En esta línea, y para obtener un modelo adecuado para la constitución, tres ligas griegas fueron de interés para los delegados de la convención de Filadelfia: la liga licia, la liga aquea y la Anfictionía de Delfos. Los últimos dos modelos fueron los que más debate suscitaron, en particular, el de la Anfictionía de Delfos. Si bien un mayor análisis de fuentes hubiera ayudado a entender mejor la problemática sobre el arquetipo griego para la formulación de la constitución estadounidense, la utilización del pasado clásico nos muestra que este pasado fue un elemento esencial para los padres fundadores de Estados Unidos en su necesidad de construir un futuro político fuerte para la naciente nación.

"La Historia de Grecia de Georges Grote y la Atenas de los liberales" de Laura Sancho Rocher es el tercer artículo de esta sección. En él, la autora se propone analizar e ilustrar el interés del modelo democrático ateniense en la obra de George Grote, que tuvo gran influencia en la intelectualidad británica y europea en el marco de la doctrina de los liberales ingleses del siglo XIX. Los liberales veían a Atenas como un modelo opuesto al conservadurismo monárquico inglés y que iba acorde a la doctrina unitaria liberal (libertad individual, participación política, gobierno representativo, democracia pura). La obra de Grote tiene una declarada tendencia política en este sentido, estableciendo una relación entre la democracia y el desarrollo artístico, científico y filosófico de Atenas. Grote utilizó fundamentalmente a Tucídides y a Demóstenes en el desarrollo de su obra estableciendo un relato netamente positivo sobre la democracia ateniense y que iba acorde a los ideales liberales de la época. En esta línea, la obra de Grote establece el nexo entre la actividad política de los ciudadanos y la gran eclosión cultural ateniense. La democracia ateniense, como modelo a seguir en contra del conservadurismo monárquico, es la base liberal para avanzar hacia un gobierno fundamentalmente representativo.

El último artículo, "Los mitos de Pompeya: arqueología y fantasía" de Mirella Romero Recio, nos lleva al análisis de cómo se ha alimentado la imaginación de la ciudad 
romana a lo largo del siglo XIX. Fue durante esos siglos cuando se erigieron los mitos más recurrentes acerca de aquella ciudad fundamentalmente a través de las novelas del romanticismo. La obra de Bulwer-Lytton, Los últimos días de Pompeya, fue la referencia elemental para todos los curiosos que visitaban el yacimiento, así como también para pintores y futuros cineastas. Cada nuevo hallazgo arqueológico alimentaba aún más la imaginación de los escritores y sorprendía a los visitantes del sitio construyendo la figura de una Pompeya mítica y alejada de los datos verídicos. Si bien los nuevos estudios de la ciudad han demostrado la fantasía de esos relatos, Romero Recio establece que estos mitos permitieron la conversión de Pompeya en uno de los lugares más famosos del mundo.

La segunda sección del libro se centra en el siglo XX. Titulada "Las quimeras historiográficas del siglo XX", la misma incluye tres artículos que se detienen en el análisis de gobiernos totalitaristas en Europa y en el del neoconservadurismo norteamericano del siglo pasado.

Antonio Duplá Ansuategui nos muestra en su "La Roma del fascismo" la utilización por parte del gobierno de Mussolini del pasado imperial romano. La “usurpación moderna de la cultura clásica" para justificar un gobierno es, en el caso italiano, uno de los más notorios. El fascismo italiano tiene, entre sus principales objetivos, el restablecimiento del Imperio Romano como un anhelo fundamental para la grandeza del pueblo italiano. El imperialismo italiano se justifica netamente con el fin de reinstaurar el Imperio de Augusto. En la producción historiográfica un elemento clave es el estudio de grandes personajes romanos que podían servir de modelo para el presente siendo esencial la figura de Augusto. La tarea del Istituto Nazionale di Studi Romani y la revista Roma fue, precisamente, la de resaltar la figura de Augusto comparándolo con Il Duce y la de establecer la romanidad fascista como un modelo civilizador justificando así las ambiciones imperialistas del régimen.

El modelo imperialista romano también es utilizado por el nazismo. Así lo analiza Salvador Mas Torres en su artículo "Roma Nacionalsocialista". La historia de Roma es vista por el Führer como la "maestra para todos los tiempos". En esta línea, el arquetipo romano era el estructurador para el partido nazi haciendo una clara comparación entre Augusto y Hitler. La producción historiográfica de la época nazi (1933-1945) utilizó el pasado clásico romano con la expresa necesidad de emular a Roma en la construcción de un "gran espacio europeo", como lo señala Ernst Kornemann. ${ }^{1}$ En este sentido, la comparación también equipara a enemigos de Alemania con rivales romanos: Cartago, por ejemplo, es comparada por Eduard Meyer con Inglaterra, que se enfrenta a Alemania (Roma). Utilizando esta referencia de Meyer, que sirve como antecedente a la producción historiográfica del régimen, vemos cómo Alemania debe emular a sus antepasados romanos debido a las circunstancias que se presentan y dominar el resto de Europa según el arquetipo imperial romano.

\footnotetext{
${ }^{1}$ También los nazis utilizaron a fondo el modelo griego. Esto se puede ver en Chapoutot (2013). 
Cierra esta sección el artículo de Pedro López Barja de Quiroga, “Leo Strauss y la Antigüedad Neocon". En él se analizan, primero, los lineamientos de la doctrina de Leo Strauss (esoterismo y antiliberalismo) y los casos griego y romano que intentaban imitar los neoconservadores estadounidenses de la época de Reagan. Ambos arquetipos clásicos responden a un papel legitimador de la política imperial norteamericana: Roma como un caso de imperialismo "benevolente" a emular y, o Grecia que viene a justificar la superioridad occidental sobre los "nuevos bárbaros" y construir el nuevo orden mundial. Estos casos vienen de la mano con la necesidad de imponerse sobre los actuales enemigos del gobierno estadounidense, Afganistán e Iraq, y de demostrar, una vez más, la superioridad de Occidente por sobre Oriente.

La tercera y última sección del libro se titula "Esencialismos y ficciones contemporáneos" y se compone de tres artículos que abordan la construcción de mitos e identidades a través de tres casos como la India, el cristianismo primitivo y el pasado celta.

El primer artículo es de Fernando Wulff Alonso y se titula "Cuando Hércules le espantaba las moscas a Buda. Negando el mundo grecorromano en la India". Este artículo es muy llamativo, ya que nos presenta una idea muy particular: la India, lejos de lo que podamos llegar a creer, debería formar parte del paisaje habitual de los estudios grecorromanos. Pero no lo forma. La pregunta central de este artículo es, en simples palabras, ¿por qué se niega el pasado grecorromano en la India? Y, secundariamente, ¿qué llevó a esta negación? Las respuestas se encuentran necesariamente en la construcción de la historia india en los últimos siglos, tanto por parte de los occidentales como de los indios. Lo más elemental para entender este paradigma negacionista o "aislacionista" es la idea de la necesidad de construir una "identidad india", única desde la Antigüedad hasta el presente. En este sentido, dos modelos confluyen para la constitución de un pasado indio: la construcción identitaria del indio y la identificación de esta identidad con un pasado único. Por ello, la continuidad de la esencia india supone el rechazo a aceptar el impacto grecorromano en la antigüedad hindú para así poder construir un pasado único $\mathrm{y}$, claramente, una identidad específica apartada de los modelos grecorromanos.

El segundo artículo, "Mujeres en el cristianismo primitivo: entre la historia y el mito feminista contemporáneo" de Gonzalo Fontana Elboj, analiza la confluencia de discursos feministas dentro de la historiografía del cristianismo primitivo. De esta manera, Fontana Elboj nos comenta que es fundamental estudiar las posiciones de las investigadoras feministas en relación con el mito y la historia cristianas. Varios son los puntos que confluyen en la producción historiográfica feminista acerca del uso del cristianismo, en especial, la labor de la mujer cristiana y el cristianismo como factor liberador de la mujer. El autor analiza, además, las lecturas feministas más actuales y cómo el mito cristiano en la producción historiográfica se renueva acorde a las posturas de las investigadoras.

El último artículo corresponde a Silvia Alfayé y se titula "Imposturas célticas: celtismo, estereotipos salvajes, druidas, megalitos y melancolías neoceltas". En él, la autora se propone abordar el fenómeno del celtismo y las interpretaciones y usos que tanto de 
la historia como de la religión céltica antigua han hecho los contemporáneos de las sociedades modernas. En esta línea, se ha "abusado" tanto de la historia como de la religión de los celtas en pos de construir identidades basadas en una tradición céltica inventada de la cual se apropian. Estas concepciones o "melancolías neocélticas", como las llama la autora, se inscriben en una serie de distorsiones, invenciones, ficciones mitologizantes y concesiones folklóricas que funcionan como legitimadoras de un pasado céltico que, en realidad, nunca existió y que trae aparejadas acciones repudiables (que incluyen actos xenófobos y violentos). Alfayé analiza estos estereotipos que funcionan como constructores de una "Céltica fantástica" y de ideales políticos, identitarios, religiosos y hasta sociales en pos de seguir un modelo céltico inexistente. Los antiguos celtas, sus culturas, su religión y sus identidades antiguas son utilizados por los contemporáneos para expresar, actualmente, identidades y sentimientos de pertenencias, construir reivindicaciones políticas y realizar utopías basándose en estereotipos sin sentido y que, en la historia celta, no existieron. Estas "melancolías celtas" son una herramienta fuerte para aquellos que buscan una referencia cultural, política y espiritual que permita legitimar una identidad neocelta en la actualidad.

En conclusión, esta compilación de artículos nos permite ver cómo son posibles la apropiación y los usos de la historia grecorromana, a lo largo de tres siglos, para servir a determinados proyectos, ideas o poderes. La antigüedad clásica ha servido a determinados historiadores y pensadores modernos en pos de presentar a Grecia y a Roma como paradigmas para sus respectivas sociedades. El pasado clásico se establece, en consecuencia, como un modelo a imitar de acuerdo a determinados objetivos, ya sea buscar un arquetipo para la formulación de una constitución, como señala el artículo de Martínez Maza, ya sea para legitimar políticas fascistas e imperialistas, como se aborda en la segunda sección del libro. La recreación de pasados inexistentes va de la mano con estos objetivos, más aún cuando se pretende construir identidades propias basadas en mundos ideales o fantásticos, como se puede observar en la tercera sección. Este trabajo, finalmente, nos permite aproximarnos a estos usos y abusos de la antigüedad clásica en un mundo moderno que busca modelos para construirse y legitimar sus acciones.

\section{Referencias bibliográficas}

Chapoutot, J. (2013). El nacionalsocialismo y la Antigüedad. Madrid: Abada Editores.

Mauro Gabriel Arévalo

Universidad Nacional de Córdoba

mauro.gabrielarevalo@gmail.com

Anuario de la Escuela de Historia Virtual - Año 9 - N 14 - 2018: pp. 132-136. ISSN: 1853-7049 